\title{
BAGAÇO DE MANDIOCA COM OU SEM COMPLEXO ENZIMÁTICO EM DIETAS DE FRANGOS DE CORTE
}

\author{
CASSAVA BAGASSE IN BROILER DIETS WITH OR WITHOUT ADDITION OF \\ ENZYMECOMPLEX
}

Sousa, J.P.L. ${ }^{*}$; Rodrigues, K.F. ${ }^{2 A}$; Albino, L.F.T. ${ }^{3} ;$ Vaz, R.G.M.V. ${ }^{2 B}$; Da Silva, G.F. ${ }^{2 \mathrm{C}}$; Siqueira, J.C. ${ }^{4}$; Santos Neta, E.R. ${ }^{5}$; Parente, I.P. ${ }^{6 A}$; Amorim, A.F. ${ }^{1 A}$ e Da Silva, M.C. ${ }^{6 B}$

\begin{abstract}
${ }^{1}$ Instituto Federal de Educação, Ciência e Tecnologia do Tocantins. Campus Dianópolis. Dianópolis, Tocantins. jpzoot24@yahoo.com.br; ${ }^{1 A}$ alineamorim19@hotmail.com

2Universidade Federal do Tocantins. Escola de Medicina Veterinária e Zootecnia. Departamento de Zootecnia. Araguaína, Tocantins. Brasil. 2A rodrigueskf@mail.uft.edu.br; ${ }^{2 B}$ robertavaz@mail.uft.edu.br; ${ }^{2 \mathrm{C}}$ gerson@uft.edu.br

3Universidade Federal de Viçosa. Departamento de Zootecnia. Viçosa. Minas Gerais. Brasil. lalbino@ufv.br ${ }^{4}$ Universidade Federal do Maranhão. Departamento de Zootecnia. Chapadinha. Maranhão. Brasil. jeferjuca@hotmail.com

${ }^{5}$ Universidade Federal Rural da Amazonas. Departamento de Zootecnia. Paragominas. Pará. Brasil. tina.neta@yahoo.com.br

${ }^{6}$ Universidade Federal do Tocantins. Pós Graduação em Ciência Animal Tropical. Araguaína. Tocantins. Brasil.6Aiberepereira@hotmail.com;6Bmonicalixto_@hotmail.com
\end{abstract}

\section{PalaVRas chaVe ADICIONAIS}

Avicultura. Desempenho. Resíduo.

\section{RESUMO}

Objetivou-se avaliar a utilização de bagaço de mandioca (BM) em rações suplementadas com complexo enzimático (CE) para frangos de corte em duas fases. Foram avaliados o ganho de peso (GP), consumo de ração (CR) e conversão alimentar (CA) de frangos de corte nas fases de 1 a 21 e 22 a 40 dias, alimentados com rações contendo 0 e $20 \%$ de inclusão de BM com e sem adição de CE. Os experimentos foram realizados num delineamento experimental em blocos casualizados com 4 tratamentos utilizando um arranjo fatorial $2 \times 2$ ( 0 e $20 \%$ de BM, com e sem CE) com 8 repetições e 20 aves por unidade experimental. Não foi observada interação entre os tratamentos, inclusão de BM e CE. A inclusão do BM diminuiu o CR e o GP em ambas as fases de criação. Enquanto que a inclusão do CE melhorou o GP e a CA das aves na fase inicial, não afetando o desempenho na fase de 22 a 40 dias de idade, já menor custo de ração por quilograma de ganho de peso e os melhores índices de eficiência econômica e de

\section{AdDitionAL KEYWORDS}

Poultry. Performance. Residue. custo para ambas as fases foi encontrado para os animais que foram submetidos a rações com $0 \%$ de inclusão de bagaço de mandioca com adição de complexo enzimático.

\section{SUMMARY}

The present work was conducted to evaluate the use of cassava bagasse (BM) in rations with enzyme complex (CE) as supplement for broilers in two phases. Two experiments were conducted to assess the weight gain (GP), feed intake (CR) and feed conversion (CA) in the phases 1-21 and 22-40 days of age, of broilers receiving diets containing 0 and $20 \%$ of $\mathrm{BM}$ and, with or without CE. The experiments were conducted in a completely randomized block design with 8 replicates and 20 broiler per experimental unit using a $2 \times 2$ factorial arrangement $(0$ and $20 \%$ of $\mathrm{BM}$, with or without $\mathrm{CE}$ ). There was no interaction between treatments, inclusion of BM and CE. The 
inclusion of BM decreased $\mathrm{CR}$ and GP in both phases. Whereas the inclusion of CE improved GP and CA at the initial stage did not affect the performance at 22-40 days of age, the cost of feed per kilogram of weight gain was lower and the rates of economic efficiency and cost for both phases was better in animals subjected to diets with $0 \%$ of cassava bagasse inclusion with the enzymatic complex.

\section{INTRODUÇÃO}

Como forma de minimizar o custo das dietas a base de milho e farelo de soja alguns autores apontam a possibilidade de utilização de subprodutos (Santos Neta et al., 20011) provenientes do processamento da mandioca como ingrediente dessas rações, reduzindo especialmente a inclusão do milho (Costa et al., 2009; Campelo et al., 2009; Freitas et al., 2008; Maciel et al. 2008; Cruz et al., 2006).

Os subprodutos da mandioca, dentro deles o bagaço da mandioca, são descartes sólidos gerados a partir da retirada da fécula e, em geral, apresentam em torno de 3625 $\mathrm{kcal} / \mathrm{kg}$ de energia bruta, $2450 \mathrm{EM} / \mathrm{kg}$ (Embrapa, 1991) e $80 \%$ de amido (Leonel et al., 1998), o qual, poderia ser aproveitada na alimentação de aves.

No entanto, o uso desses subprodutos pode afetar o desempenho dos animais provavelmente devido à redução na disponibilidade de nutrientes da dieta causado pela presença de fibras solúveis e insolúveis nesses subprodutos. Essas fibras possuem a capacidade de aumentar o arraste dos nutrientes ingeridos para as fezes, como os minerais, as proteínas, os lipídeos e os carboidratos digestíveis, restringindo o seu aproveitamento pelo organismo. Salienta-se que essas alterações são resultado tanto dos constituintes da fibra, bem como pela proporção desses componentes da fração fibra da dieta (Raupp et al., 2002).

Contudo, no intuito de melhorar o aproveitamento dos nutrientes pelos frangos de corte, alguns autores recomen- dam o uso de enzimas exógenas que podem melhorar o aproveitamento da digesta (xilanase, pectinases e glucanases), a degradação da celulose (celulases), das proteínas (proteases), do amido (amilases) e a utilização do fósforo (fitase) (Oliveira $e t$ al., 2009; Caires et al., 2008).

Sabendo-se do potencial fornecedor de energia e amido do bagaço de mandioca para a nutrição de aves, com isso, faz-se necessário o uso de enzimas exógenas para melhor aproveitamento deste ingrediente (Tavernari et al., 2008).

Portanto, objetivou-se com esse trabalho avaliar o desempenho de frangos de corte nas fases de $1^{\circ}$ a $21^{\circ}$ e de $22^{\circ}$ a $40^{\circ}$ dia de idade da adição de bagaço de mandioca, com ou sem adição de complexo enzimático e os Índice de eficiência econômico e de custos.

\section{MATERIALEMÉTODOS}

Dois experimentos foram conduzidos no setor de avicultura no Departamento de Zootecnia da Universidade Federal de Viçosa. Inicial (1 a 21 dias) e crescimento (22 a 40 dias).

Em ambos os experimentos as aves foram distribuídas em um delineamento em blocos ao acaso (DBC) de forma minimizar o efeito da insolação dentro do galpão, pois o galpão utilizado é orientado no sentido norte-sul. O galpão utilizado é de alvenaria, telado e coberto com telha de barro, subdividido em boxes de 1,0 x 1,5 metros coberto com cama de maravalha e providos de um bebedouro tipo Nipple e um comedouro tubular. Ambas foram realizadas em esquema fatorial $2 \times 2(0$ e $20 \%$ de BM x com e sem CE) sendo quatro tratamentos, com 8 repetições e 20 aves por unidade experimental.

As aves foram criadas segundo o manual da linhagem $C o b b$, sendo registrada a mortalidade para ser considerado durante a correção dos dados de consumo de ração. A temperatura máxima e mínima foi monitorada diariamente durante todo o período experimental. 


\section{BAGAÇO DE MANDIOCA COM ENZIMA PARA FRANGOS DE CORTE}

As rações foram a base de milho e farelo de soja, formuladas para atender as exigências nutricionais das aves na fase de 1 a 21 e de 22 a 40 dias de idade segundo Rostagno et al. (2005) Os valores do bagaço de mandioca foram considerados segundo Embrapa (1991) (tabela I).

O bagaço de mandioca utilizado foi obtido após o processamento das raízes de mandioca compreendendo as etapas de lavagem, descascamento das raízes, desintegração das células e liberação dos grânulos de amido, separação das fibras e do material solúvel e finalmente, a secagem. Ao final o material continha $88,72 \%$ de matéria seca (MS), 1,5\% de proteína bruta (PB), 11,10\% de fibra bruta (FB) e 2973 $\mathrm{kcal} / \mathrm{kg}$ de energia metabolizável.

O complexo enzimático utilizado foi o Allzyme SSF® que é produzido a partir do

Tabela I. Composição percentual e química das rações da fase inicial e crescimento (com base na matéria natural). (Percentage and chemical composition of the diets of early stage and growth (based on fresh matter)).

\begin{tabular}{|c|c|c|c|c|}
\hline & \multicolumn{2}{|c|}{ Fase inicial } & \multicolumn{2}{|c|}{ Fase de crescimento } \\
\hline & $0 \%$ & $20 \%$ & $0 \%$ & $20 \%$ \\
\hline \multicolumn{5}{|l|}{ Ingredientes (\%) } \\
\hline Milho & 55,298 & 26,910 & 60,577 & 30,896 \\
\hline Farelo de soja & 37,919 & 42,177 & 31,504 & 36,886 \\
\hline Bagaço de mandioca & 0,000 & 20,000 & 0,000 & 20,000 \\
\hline Óleo de soja & 2,944 & 7,194 & 4,242 & 8,726 \\
\hline Fosfato bicálcico & 1,824 & 1,905 & 1,653 & 1,729 \\
\hline Calcário & 0,843 & 0,635 & 0,834 & 0,623 \\
\hline Sal comum & 0,492 & 0,504 & 0,470 & 0,482 \\
\hline DL-Metionina 99\% & 0,236 & 0,283 & 0,224 & 0,263 \\
\hline L-lisina $\mathrm{HCl} 99 \%$ & 0,099 & 0,036 & 0,154 & 0,057 \\
\hline L-Treonina $98 \%$ & 0,010 & 0,021 & 0,027 & 0,023 \\
\hline Premix vitamínico ${ }^{1}$ & 0,120 & 0,120 & 0,100 & 0,100 \\
\hline Premix mineral $^{2}$ & 0,050 & 0,050 & 0,050 & 0,050 \\
\hline Cloreto de colina $60 \%$ & 0,100 & 0,100 & 0,100 & 0,100 \\
\hline Anticoccidiano (salinomicina 12\%) & 0,055 & 0,055 & 0,055 & 0,055 \\
\hline Antioxidante $^{3}$ & 0,010 & 0,010 & 0,010 & 0,010 \\
\hline Total & 100,00 & 100,00 & 100,00 & 100,00 \\
\hline \multicolumn{5}{|l|}{ Composição calculada } \\
\hline Materia seca & 88,26 & 90,76 & 88,33 & 88,89 \\
\hline Energia metabolizável, kcal/kg & 3000 & 3000 & 3150 & 3150 \\
\hline Proteína bruta, \% & 21,99 & 21,85 & 19,58 & 19,79 \\
\hline Fibra bruta, \% & 3,01 & 4,97 & 2,75 & 4,75 \\
\hline Cálcio, \% & 0,88 & 0,88 & 0,82 & 0,82 \\
\hline Metionina + cistina, \% & 0,84 & 0,84 & 0,77 & 0,77 \\
\hline Lisina, \% & 1,16 & 1,16 & 1,05 & 1,05 \\
\hline Fósforo total, \% & 0,67 & 0,73 & 0,67 & 0,73 \\
\hline Fósforo disponível, \% & 0,45 & 0,45 & 0,41 & 0,41 \\
\hline
\end{tabular}

${ }^{1}$ Mistura vitamínica (kg do produto): vit. A: 10.000 .000 U.I.; vit. D3: 2.000 .000 U.I.; vit. E: 30.000 U.I.; vit. B1: 2,0 g; vit. B2: $6,0 \mathrm{~g}$; vit. B6: $4,0 \mathrm{~g}$; vit. B12: $0,015 \mathrm{~g}$; ác. pantotênico: $12,0 \mathrm{~g}$; biotina: $0,1 \mathrm{~g}$; vit. K3: 3,0 g; ác. fólico: $1,0 \mathrm{~g}$; ác. nicotínico: $50,0 \mathrm{~g}$; Se: $250,0 \mathrm{mg}$. ${ }^{2}$ Mistura mineral (kg do produto): $\mathrm{Fe}: 80 \mathrm{~g}$; Cu: 10 g; Co: 2 g; Mn: 80 g; Zn: 50 g; I: 1 g. ${ }^{3}$ Antioxidante: BHT (Butil hidroxi tolueno). 
fungo Aspergillus niger, composto pelas enzimas fitase, protease, xilanase, $\beta$ glucanase, celulase, amilase e pectinase na dosagem de $200 \mathrm{~g} /$ ton de ração.

Os tratamentos foram caracterizados da seguinte forma: Tratamento $1-0 \%$ de inclusão de bagaço de mandioca; Tratamento 2 $0 \%$ de inclusão do bagaço de mandioca + complexo enzimático (200 g/ton); Tratamento 3 - $20 \%$ de inclusão do bagaço de mandioca; Tratamento 4 - $20 \%$ de inclusão de bagaço de mandioca + complexo enzimático (200 g/ton).

Foram utilizados 1280 frangos de corte machos da linhagem Cobb 500. No primeiro experimento foram utilizados 640 pintos de corte de um dia de idade com peso médio de 39,89 g. No segundo experimento os pintinhos foram criados, do $1^{\circ}$ a $21^{\circ}$ dia de idade, em galpão fechado recebendo água e ração a vontade segundo recomendações do manual da linhagem Cobb 500. No $22^{\circ}$ dia esses animais foram pesados e selecionados 640 frangos com peso médio de $836,95 \mathrm{~g}$.

As aves e as dietas foram pesadas no início e no final do período experimental, para avaliar o ganho de peso (GP) e o consumo de ração (CR) para calcular a conversão alimentar (CA).

Para verificar a viabilidade econômica dos dois ensaios, determinou-se o custo da ração por quilograma e ganho de peso (Yi), segundo Bellaver et al. (1985).

Em que,

$$
Y i=\left(P i^{*} Q i\right) / G i
$$

$Y \mathrm{i}=$ custo da ração por quilograma de ganho de peso no i-ésimo tratamento;

$\mathrm{Pi}=$ preço por quilograma da ração utilizada no iésimo tratamento;

$\mathrm{Qi}=$ quantidade de ração consumida no i-ésimo tratamento;

$\mathrm{Gi}=$ ganho de peso no i-ésimo tratamento.

Em seguida foram calculados o Índice de Eficiência Econômico (IEE) e o Índice de Custo (IC), de acordo com Fialho et al. (1992).
$\mathrm{IEE}=(\mathrm{MCe} / \mathrm{CTei})^{*} 100$;

$\mathrm{IC}=(\mathrm{CTei} / \mathrm{MCe})^{*} 100$.

Em que

$\mathrm{MCe}=0$ menor custo da ração por quilograma de ganho observado entre os tratamentos.

$\mathrm{CTe}=$ custo do tratamento $\mathrm{i}$ considerado .

As análises estatísticas das variáveis estudadas foram realizadas utilizando-se o software SAS 9.0 - por meio do procedimento GLM (General Linear Models) (SAS, 1998).

\section{RESULTADOSEDISCUSSÃO}

Os resultados obtidos no experimento (1 a 21 dias de idade) são apresentados na tabela II. Como pode ser observada não houve interação $(p>0,05)$ bagaço de mandioca (BM) e complexo enzimático (CE) consumo de ração (CR), ganho de peso (GP) e conversão alimentar (CA).

Os frangos alimentados com ração contendo $20 \%$ de inclusão do BM apresentaram consumo de ração (CR) $7 \%$ inferior $(\mathrm{p}<0,05)$ em relação aos frangos que receberam a ração sem a inclusão de BM independente do complexo enzimático. Esta diminuição no consumo pode ser pelo aumento na quantidade de óleo de soja na ração de $20 \%$ de inclusão de BM, que pode estimular a produção de colecistoquinina (CCK), hormônio que causa inibição na fome, interferindo assim o consumo (Furlan e Macari, 2002). Essa afirmação esta de acordo com Nascimento et al. (2005) que encontraram em frangos de corte, menor consumo de ração utilizando raspa de mandioca em substituição ao milho.

Outro ponto relevante é que o BM, por apresentar alto teor de fibra bruta $(11 \%$ a 14 $\%$ ), pode alterar a densidade da ração, e aumentar a capacidade de absorção de água. Essas características afetam a ingestão de alimento pelo volume ocupado no trato digestivo (Braga et al., 2005). Esse efeito volumoso da fibra pode explicar os resultados obtidos neste experimento, uma vez que o teor de fibra das dietas aumentou com a 


\section{BAGAÇO DE MANDIOCA COM ENZIMA PARA FRANGOS DE CORTE}

Tabela II. Consumo de ração (CR), ganho de peso $(G P)$ e, conversão alimentar $(C A)$ de frangos de corte de 1 a 21 dias recebendo dietas contendo ou não bagaço de mandioca (BM), com ou sem adição complexo enzimático (CE). (Feed intake (CR), weight gain (GP) and feed conversion (CA) of broilers from 1 to 21 days or not receiving diets containing cassava bagasse (BM), with or without added enzyme complex (CE)).

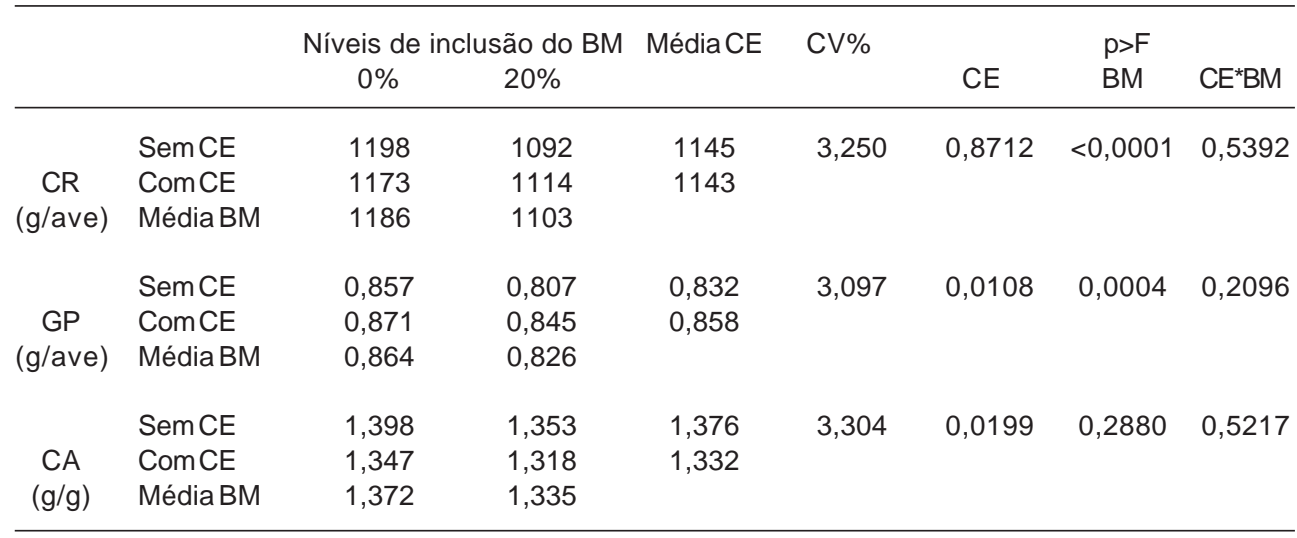

$p>F=$ teste $F$ da análise de variância; $C V=$ Coeficiente de variação.

inclusão de $20 \%$ do BM, atingindo 4,97 \% o que pode provocar entre outros problemas um maior arraste e menor aproveitamento de nutrientes (Raupp et al., 1997).

Da mesma forma a inclusão de BM na ração reduziu $(\mathrm{p}<0,05)$ em 4,39\% o ganho de peso (GP) das aves. Contrário a isso a inclusão de $20 \%$ de BM na dieta de frangos não influenciou a $\mathrm{CA}$, pois a medida que aumentou CR e GP na ração $0 \%$ BM houve uma diminuição proporcional no CR e GP da ração $20 \%$ de $\mathrm{BM}$.

A inclusão de CE não afetou ( $p>0,05) o$ CR dos frangos de corte. No entanto, melhorou em $3,03 \%$ o GP $(p<0,05)$ dos frangos independente do uso do BM, mostrando que o uso de CE melhora a disponibilidade dos nutrientes e isso reflete em melhor desempenho. Resultados semelhantes foram obtidos por Oliveira et al. (2007), usando CE em rações à base de milho e farelo de soja, porém, contraditórios aos encontrados no presente estudo também foram observados por Silva et al. (2000) que constataram que a suplementação com complexo enzimático $(\alpha$-glucanase, pectina- se, hemicelulase e amilase) não melhorou o GP de frangos de corte na fase de 1 a 21 dias de idade com rações com níveis de $0,5,17$ e $10,34 \%$ de farinha de folhas de mandioca.

A CA melhorou em 3,19\% com a adição de CE ( $p<0,0199)$. Segundo Silva et al. (2000) isso pode ocorrer pois a atividade das enzimas xilanase, $\beta$-glucanase, celulase e pectinase são de ação específica para dietas fibrosas, proporcionando assim melhora no aproveitamento dos nutrientes dos alimentos.

Os resultados mostram que o menor custo de ração por ganho de peso vivo e os melhores índices de eficiência econômica (IEE) e índice de custo (IC) foram obtidos quando os frangos foram alimentados com rações sem inclusão do BM + CE (tabela III).

O segundo melhor IEE e IC foram obtidos com $20 \%$ de inclusão do BM + adição de CE. Isso mostra que o uso de enzimas melhora a viabilidade econômica da produção de frangos de corte. No segundo experimento (22 a 40 dias de idade) a mortalidade durante esta fase foi de $1,16 \%$.

Não foi observada interação significati- 
Tabela III. Custo de ração por quilograma ganho de peso vivo (CuR), índice de eficiência econômica (IEE) e indice de custo (IC) de frangos de 1 a 21 dias de idade alimentados com rações contendo níveis diferentes de bagaço de mandioca (BM), com ou sem adição do complexo enzimático $(C E)$. (Cost of feed per kilogram live weight gain (CuR, $R \$ / \mathrm{kg} \mathrm{GP}$ ), economic efficiency index (IEE) and cost index (IC) chickens 1-21 days of age fed diets containing different levels of cassava bagasse (BM), with or without addition of the enzyme complex (CE)).

\begin{tabular}{ccccc}
\hline & \multicolumn{4}{c}{ Tratamentos } \\
& $0 \%$ BN & $0 \%$ BN + CE & $20 \%$ BN & $20 \% \mathrm{BN}+\mathrm{CE}$ \\
\hline CuR (R\$/kg de GP) & 1,061 & 1,026 & 1,060 & 1,034 \\
IEE & 96,51 & 100,00 & 96,79 & 99,22 \\
IC & 103,60 & 100,00 & 103,31 & 100,77 \\
\hline
\end{tabular}

Data de cotação do dólar dos EUA, em 30/10/2010, onde 1 real = 0,59 dólar e 1 dolar $=1,68$ reais

va $(p>0,05)$ para bagaço de mandioca $(B M)$ e complexo enzimático (CE) para consumo de ração (CR), ganho de peso (GP) e conversão alimentar (CA) (tabela IV).

A inclusão de $20 \%$ de BM nas rações reduziu ( $\mathrm{p}<0,05)$ em 7,38\% o CR, estando de acordo com a fase inicial de 1 a 21 dias de idade. O mesmo ocorreu com o GP que reduziu $(\mathrm{p}<0,05)$ em $6,91 \%$, podendo essa redução no GP ser explicada pela redução no consumo. Campelo et al. (2009) avaliando níveis crescentes de inclusão da farinha de raspa de mandioca $(0,18,36$ e $53 \%)$ em rações para frangos de corte caipiras na fase de 30 a 80 dias de idade encontraram diminuição no peso final das aves. Já a CA não foi influenciada $(\mathrm{p}>0,05)$ pela inclusão de $20 \%$ de BM, sendo proporcional à diminuição do GP e do CR.

A inclusão de CE não influenciou ( $p>0,05$ ) o CR, GP e CA, podendo ser explicado pelo fato da ave estar com seu trato

Tabela IV. Resultados de consumo de ração $(C R)$, ganho de peso $(G P)$ e, conversão alimentar (CA) de frangos de corte de 22 a 40 dias recebendo dietas contendo ou não bagaço de mandioca (BM), com ou sem adição complexo enzimático $(C E)$. (Results of feed intake (CR), weight gain (GP) and feed conversion (CA) of broilers from 22 to 40 days or not receiving diets containing cassava bagasse (BM), with or without added enzyme complex (CE)).

\begin{tabular}{|c|c|c|c|c|c|c|c|c|}
\hline & & \multicolumn{2}{|c|}{ Níveis de inclusão do BM } & \multirow[t]{2}{*}{ Média CE } & \multirow[t]{2}{*}{ CV\% } & \multicolumn{3}{|c|}{$p>F$} \\
\hline & & $0 \%$ & $20 \%$ & & & CE & BM & $C E^{\star} B M$ \\
\hline & Sem CE & 2317 & 2228 & 2273 & & & & \\
\hline $\mathrm{CR}$ & ComCE & 2324 & 2171 & 2248 & 3,774 & 0,4138 & 0,0005 & 0,2997 \\
\hline \multirow{2}{*}{ (g/ave) } & X BM & 2321 & 2200 & & & & & \\
\hline & Sem CE & 1281 & 1203 & 1242 & & & & \\
\hline GP & ComCE & 1292 & 1178 & 1235 & 9,439 & 0,8775 & 0,0293 & 0,6724 \\
\hline \multirow{2}{*}{ (g/ave) } & Média BM & 1287 & 1191 & & & & & \\
\hline & SemCE & 1,808 & 1,852 & 1,830 & & & & \\
\hline $\mathrm{CA}$ & ComCE & 1,798 & 1,843 & 1,820 & 7,326 & 0,7988 & 0,2360 & 0,9958 \\
\hline$(g / g)$ & Média BM & 1,803 & 1,847 & & & & & \\
\hline
\end{tabular}

Archivos de zootecnia vol. 63, núm. 244, p. 662. 


\section{BAGAÇO DE MANDIOCA COM ENZIMA PARA FRANGOS DE CORTE}

Tabela $\boldsymbol{V}$. Custo de ração por quilograma ganho de peso vivo $(\mathrm{CuR})$, índice de eficiência econômica (IEE) e índice de custo (IC) de frangos de 22 a 40 dias de idade alimentados com rações contendo níveis diferentes de bagaço de mandioca (BM), com ou sem adição do complexo enzimático $(C E)$. (Cost of feed per kilogram live weight gain (CuR), economic efficiency index (IEE) and cost index (IC) chickens 22-40 days of age fed diets containing different levels of cassava bagasse $(B M)$, with or without addition of the enzyme complex (CE)).

\begin{tabular}{ccccc}
\hline & \multicolumn{4}{c}{ Tratamentos } \\
& $0 \%$ BN & $0 \%$ BN + CE & $20 \%$ BN & $20 \% \mathrm{BN}+\mathrm{CE}$ \\
\hline CuR (R\$/kg de GP) & 1,342 & 1,336 & 1,470 & 1,467 \\
IEE & 99,25 & 100,00 & 90,47 & 91,09 \\
IC & 100,75 & 100,00 & 110,52 & 99,31 \\
\hline
\end{tabular}

Data de cotação do dólar dos EUA, em 30/10/2010, onde 1 real= 0,59 dólar e 1 dolar= 1,68 reais.

gastrointestinal completamente desenvolvido nessa fase, suprindo suas necessidades enzimáticas, não aproveitando de forma significativa os efeitos do uso das enzimas exógenas. Igualmente, Strada et al. (2005) observaram que o CR pelas aves não foi influenciado pela adição de CE em dietas a base de farelo de soja e sorgo ou farelo de soja e milheto na ração de frangos de corte na fase de 22 a 42 dias de idade, concluindo que, a inclusão de complexo enzimáticos, tanto em rações à base de farelo de soja e sorgo como à base de farelo de soja e milheto, não proporcionou melhor GP em frangos de corte. Lima et al. (2002), que ao suplementarem as dietas com amilase e protease, não encontraram diferenças na conversão alimentar no período de 1 a 42 dias de idade.

Os resultados mostram que o menor custo de ração por ganho de peso e os mel-

\section{BIBLIOGRAFIA}

Bellaver, C.; Fialho, E.T.; Protas, J.F.S. e Gomes, P.C. 1985. Radícula de malte na alimentação de suínos em crescimento e terminação. Pesq Agropec Bras, 20: 969-974.

Braga, C.V. de P.; Fuentes, M. de F.F.; Freitas, E.R.; Carvalho, L.E. de; Sousa, F.M. de e Bastos, S.C. 2005. Efeito da inclusão do farelo de coco em rações para poedeiras comerciais. Rev Bras Zootecn, 34: 76-80. hores índices de eficiência econômica (IEE) e índice de custo (IC) foram obtidos quando os frangos foram alimentados com rações sem inclusão do bagaço de mandioca, com $\mathrm{CE}$. Isso evidencia que o uso de complexo enzimático é eficiente economicamente em rações para frangos de corte (tabela $\mathbf{V}$ ).

Portanto, pode-se concluir que a inclusão do bagaço de mandioca possibilita desempenho inferior comparado aos frangos mantidos com dietas a base de milho e farelo de soja em ambas as fases de criação. Enquanto que o desempenho na fase inicial foi superior nos tratamentos com inclusão do complexo enzimático não apresenta efeito na fase de 22 a 40 dias de idade. O nível de $0 \%$ de inclusão mais CE apresentou o menor custo de ração por quilograma de ganho de peso e os melhores índices de eficiência econômica e de custo para ambas às fases.

Caires, C.M.; Fagundes, N.S.; Fernandes, E. de A. e Carvalho, A.P. de. 2008. Enzimas na alimentação de frango de corte. Rev Eletrôn Nutrtime, 5: 491-497.

Campelo, C.C.; Santos, M. do S.V. dos; Leite, A.G. dos A.; Rolim, B.N.; Cardoso, W.M. e Souza, F.M. 2009. Características de carcaça de frangos tipo caipira alimentados com dietas contendo farinha de raízes de mandioca. Ciênc Anim 
Bras, 10: 1021-1028.

Costa, F.G.P.; Goulart, C. de C.; Costa, J.S.; Souza, C.J. de; Dourado, L.R.B. e Silva, J.H.V. 2009. Desempenho, qualidade de ovos e análise econômica da produção de poedeiras semipesadas alimentadas com diferentes níveis de raspa de mandioca. Acta Sci Anim Sci, 31: 13-18.

Cruz, F.G.G.; Filho, M.P. e Chaves, F.A. de L. 2006. Efeito da substituição do milho pela farinha da apara de mandioca em rações para poedeiras comerciais. Rev Bras Zootecn, 35: 2303-2308.

Embrapa. Empresa Brasileira de Pesquisa e Agropecuaria. 1991. Tabela de composição química e valores energéticos de alimentos para suínos e aves. $3^{\underline{a}}$ ed. Centro Nacional de Pesquisa de Suínos e Aves. Embrapa. Concórdia. $97 \mathrm{pp}$.

Fialho, E.T.; Barbosa, O.; Ferreira, A.S.; Gomes, P.C. e Girotto, A.F. 1992. Utilização da cevada suplementada com óleo de soja para suínos em crescimento e terminação. Pesq Agropec Bras, 27: 1467-1475.

Freitas, C.R.G.; Ludke, M. do C.M.M.; Ludke, J.V.; Rabello, C.B.; Nascimento, G.R. do; Barbosa, E.N.R. 2008. Inclusão da farinha de varredura de mandioca em rações de frangos de corte. Acta Scient Anim Sci, 30: 155-163.

Furlan, R.L.; Macari, M. 2002. Motilidade gastrointestinal. In: Macari, M.; Furlan, R.L. e Gonzales, E. Fisiologia aviária aplicada a frangos de corte. $2^{\mathrm{a}}$ ed. FUNEP. Jaboticabal. pp. 97-103.

Leonel, M.; Cereda, M.P. e Jaquey, S. 1998. Processamento industrial de fécula de mandioca e batata-doce - um estudo de caso. Ciênc Tecnol Alim, 18: 343-345.

Lima, A.C.F.; Harnich, F.A.R.; Macari, M. e Pizauro Júnior, J.M. 2002. Avaliação do desempenho de frangos de corte alimentados com suplementação enzimática e probiótica. Ars Vet, 18: 153157.

Maciel, R.P.; Neiva, J.N.M.; Oliveira, R.C.O.; Araújo, V.L. de; Lôbo, R.N. 2008. Características fermentativas e químicas de silagem de capimelefante contendo subproduto da mandioca. Rev Ciênc Agron, 39: 142-147.

Nascimento, G.A.J. do; Costa, F.G.P.; Amarante Junior, V. da S. e Barros, L.R. 2005. Efeitos da substituição do milho pela raspa de mandioca na alimentação de frangos de corte, durante as fases de engorda e final. Ciênc Agrotec, 29:
200-207.

Oliveira, M.C. de; Cancherini, C.C.; Gravena, R.A.; Rizzo, P.V. e Morais, V.M.B. de. 2007. Utilização de nutrientes de dietas contendo mananoligossacarídeo e/ou complexo enzimático para frangos de corte. Rev Bras Zootecn, 36: 825-831.

Oliveira, M.C. de; Cancherini, C.C.; Marques, R.H.; Gravena, R.A. e Morais, V.M.B. de. 2009. Mananoligossacarídeos e complexo enzimático em dietas para frangos de corte. Rev Bras Zootecn, 38: 879-886.

Raupp, D.S.; Marques, S.H. de P.; Rosa, D.A.; Caldi, A.C. e Banzatto, D.A. 2002. Arrastre via fecal de nutrientes da ingestão produzido por bagaço de mandioca hidrolisada. Scient Agric, 59: 235-242.

Raupp, D.S. e Sgarbieri, V.C. 1997. Efeito da fibra solúvel de alta viscosidade na ingestão de alimentos, na excreção fecal e no peso corpóreo, em ratos. Braz Arch Biol Technol, 40: 863874.

Rostagno, H.S; Albino, L.F.T; Donzele, J.L; Gomes, P.C; Oliveira, R.F. de; Lopes, D.C; Ferreira, A.S e Barreto, S.L. de T. 2005. Tabelas brasileiras para aves e suínos composição de alimentos e exigências nutricionais. UFV. Imprensa Universitária. Viçosa. 186 pp.

Santos Neta, E.R.; Vaz, R.G.M.V.; Rodrigues, K.F.; de Sousa, J.P.L.; Parente, I.P.; Albino, L.F.T.; Siqueira, J.C. e Rosa, F.C. 2011. Níveis de inclusão da torta de babaçu em rações de frangos de corte na fase inicial. Rev Bras Saúd Prod Anim, 12: 234-243.

Silva, H.O.; Fonseca, R.A. da e Guedes Filho, R. de S. 2000. Características produtivas e digestibilidade da farinha de folhas de mandioca em dietas de frangos de corte com e sem adição de enzimas. Rev Bras Zootecn, 29: 823-829.

SAS. Statistical Analyses System. 1998. SAS/ INSIGHT User's guide. versão 9.1 - versão para Windows. SAS Institute. Cary.

Strada, E.S. de O.; Abreu, R.D.; Oliveira, G.J.C. de; Costa, M. do C.M. da; Carvalho, G.J.L. de; Franca, A.S.; Clarton, L. e Azevedo, J.L.M. de. 2005. Uso de enzimas na alimentação de frangos de corte. Rev Bras Zootecn, 34: 2369-2375.

Tavernari, F.C.; Carvalho, T.A.; Assis, A.P. e Lima, H.J.D. 2008. Níveis de inclusão da torta de babaçu em rações de frangos de corte na fase inicial. Rev Eletr Nutrime, 5: 673-689. 